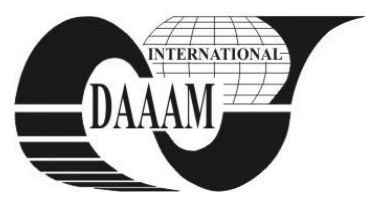

Annals of DAAAM for 2011 \& Proceedings of the 22nd International DAAAM Symposium, Volume 22, No. 1, ISSN 1726-9679 ISBN 978-3-901509-83-4, Editor B. Katalinic, Published by DAAAM International, Vienna, Austria, EU, 2011 Make Harmony between Technology and Nature, and Your Mind will Fly Free as a Bird

\title{
REVERSE ENGINEERING APPLICATION IN PRESERVATION OF CULTURAL HERITAGE
}

\author{
BAJIC, D[razen]; CELENT, L[uka] \& JOZIC, S[onja]
}

\begin{abstract}
In this paper Reverse engineering technology widely applied to industrial product development was led under the circumstance of scientific research into protection of cultural heritage. Reverse engineering was used in order to complete the missing data and reconstruct the model of ancient musical instrument named 'lira'. Measurement data are acquired by $3 D$ stereo-photogrammetric scanning. Processing the measurement data by CATIA software a CAD model was created. Final and improved model was built in CNC machining centre.
\end{abstract}

Key words: reverse engineering, surface creation, $C A D, C A M$

\section{INTRODUCTION}

In the last decade, the traditional work of archaeologists, art historians, archivists has been progressively transformed owing to the development of three-dimensional (3D) reverse modeling techniques and virtual reality. This techniques offer a powerful tool for conducting in-depth analyses, testing different hypotheses, creating databases and archives in a way that was unimaginable some time ago. Moreover, digital models make human Cultural Heritage accessible to a worldwide public and represent an invaluable means for documentation, education and preservation purposes. In literature known, an experimental work in field of Cultural Heritage was made by Fassi et al. (2007) as well as Stanford University project of Digital Michelangelo (Anderson et al., 2000). The preservation, communication, restoration and replication in Cultural Heritage have common topics with cultural patrimony. As a part of Cultural Heritage, Poklad ritual on the Lastovo Island is of the utmost meaning for the participants and takes place uninterruptedly from ancient times. Lira as an ancient musical instrument plays a crucial role through the whole ritual and represents a precious Cultural Heritage. The advent of the Cultural Heritage digital era is strictly linked to the development and integration of 3D survey.

This paper refers to the usage of reverse engineering (RE) in preservation of Cultural Heritage as well as in making it accessible to the public. Preservation of Lira as a Croatian cultural patrimony is closely related to its replication and exposure in public. In order to fulfill the original functionality of Lira the inner surface of the instrument was reconstructed, but at the same time the components were updated to add functionality.

\section{PHASES OF REVERSE ENGINEERING ON LIRA MODEL}

The goal of the first phase of RE is to capture or recreate the geometry of the object by digitization. Hong-Tzong (1997) in his work refers to the problem of digitizing the data. Strategy for digitization of the object depends on complexity of the surfaces. In RE of Lira digitization was performed by $3 \mathrm{D}$ stereo-photogrammetric scanning of original Lira. The digitized data is then processed to create the CAD model. A physical prototype (styrofoam model) is then made according to the CAD model for validation of the same. Hong-Tzong Y. (1997) and Chen \& Ng (1997) refer to the importance of physical prototype phase in RE. Final and improved product, a wooden model of Lira was built in CNC machining centre. Considering the phases of RE Sokovic \& Kopac (2006) and Cosma et al. (2009) elaborated RE in rapid product development.

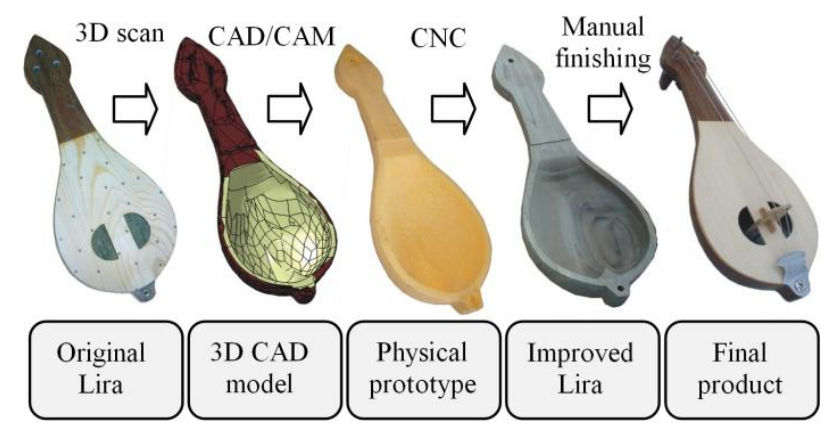

Fig. 1. General steps of RE on Lira model

\section{REVERSE ENGINEERING IN CATIA}

The use of numerous systems to develop digital products from physical prototypes is complex and costly, leading to delays in product development. There are many software about RE, like Geomagic, Surface, Imageware, and like normal 3D modeling software also included the function of Reverse engineering. CATIA RE makes possible quickly capture and enhance physical prototype shapes, making the 3D virtual model the design reference. It also provides powerful technologies embedded within CATIA that allow the easy manipulation of clouds of points or meshes, while quickly transforming them into high-end 3D surface shapes.

This paper uses CATIA V5 because of its great combination function about surface design, modeling design, reverse design and etc. In RE design there are three main modules: Digitized Shape Editor (DSE), Quick Surface Reconstruction (QSR) and Generative Shape Design (GSD). The process of RE in CATIA used in this article is shown in Fig. 2.

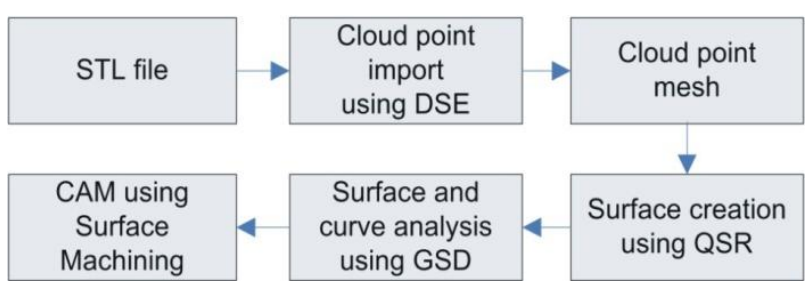

Fig. 2. The process of RE in CATIA

\subsection{Surface creation}

To solve the problem of surface creation in building the model of lira, certain requirements were taken into consideration. The purpose of the object, the required accuracy and the quality of the patch layout of the surface were considered and consequently the CATIA software was used. In order to create surface a points cloud acquired by $3 \mathrm{D}$ stereo- 
photogrammetric scanner was tessellated by CATIA software into a STL mesh. Building a surface from the STL mesh requires a good quality STL file. Szilvasi-Nagy \& Matyasi (2003) and Rypl \& Bittnar (2006) have provided extensive analysis of STL files.

Rough and noisy parts on the surface of the mesh were avoided and twisted or in any other way corrupted triangles were prevented and quality of the layout was ensured by closing all small holes. Mean surface deviation was checked and the Surface detail was set to 2000. Due to a rough edge of the mesh free edge tolerance was set to higher value of $1 \mathrm{~mm}$, also the full internal tangency was checked. Satisfying layout of the sub-surface was gained.

\subsection{CAD model and physical prototype analysis and improvements}

Involving surfaces a CAD model was created. A physical prototype is then made according to the CAD model and analyses are carried out mostly on physical prototype. Analyzing the CAD model a certain disproportions involving possible poor performance and reduce of the functionality of Lira were visible. This refers mostly to the inner design. However, disadvantages of this design are not clearly reflected in the CAD model therefore a physical prototype was important. Analyzing the physical prototype, the wall thickness of the body, was found discontinuous along the inner surface and with maximum thickness of $24 \mathrm{~mm}$.

Medial frame of Lira was also in disproportion. In order to add functionality a certain parts were reconstructed and improved. The wall thickness was reduced to $10 \mathrm{~mm}$ and made continuous along the whole inner surface (Fig.3). Medial frame was set in the center with new and improved design (Fig. 4).

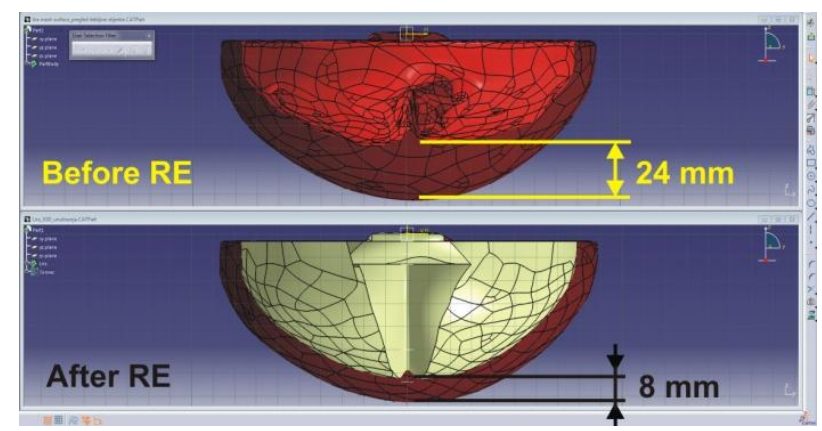

Fig. 3. Wall thickness of the Lira body in sectional view

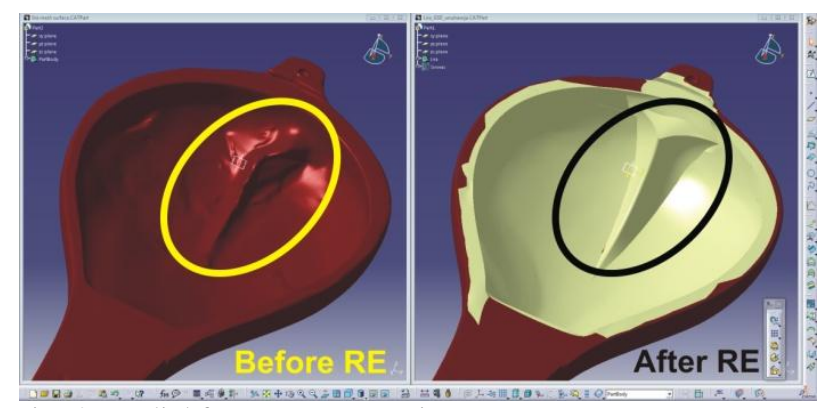

Fig. 4. Medial frame reconstruction

\subsection{Surface Machining}

CATIA module Surface Machining was used to generate NC code for machining of final product, wooden model of Lira. NC machining time was reduced thanks to optimized tool paths (Fig. 5). The type of machine used for the milling of Lira was machining center VC560 manufactured by Spinner (Fig.6). Lira was made of walnut. Considering the specifics of that same material, special attention was paid to the selection of cutting parameters.

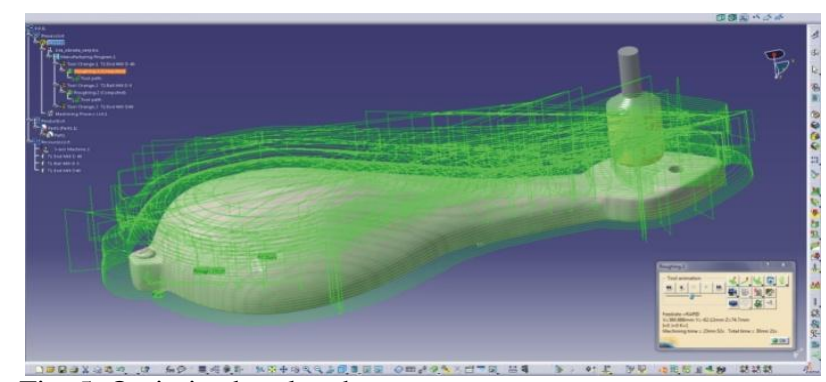

Fig. 5. Optimized tool path

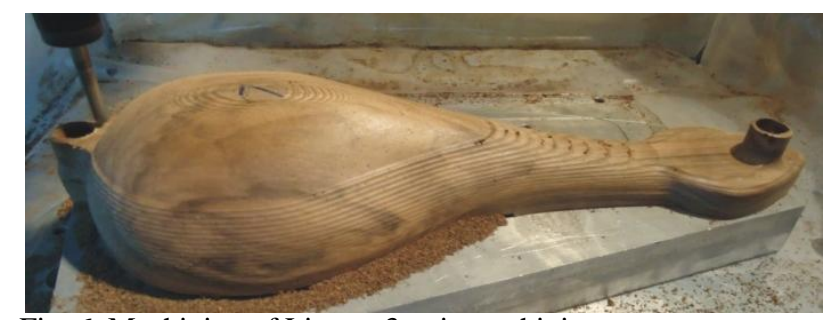

Fig. 6. Machining of Lira on 3-axis machining center

\section{CONCLUSION}

In this paper reverse engineering was successfully applied in preservation of Cultural Heritage. Using CATIA software an ancient instrument named Lira was reconstructed.This procedure showed great efficiency fulfilling all the requestments and therefore is a right methodology to approach the problem of Cultural Heritage preservation. Analyzing the prototypes the inner design of Lira was updated to add functionality in order to expose it to the public as an improved replica. Application of RE in reconstruction and replication of Lira give a starting point to future projects in the field of Cultural Heritage.

\section{REFERENCES}

Anderson, S.; Curless, B.; Davis, J.; Fulk, D.; Ginsberg, M.; Levoy, M.; Koller, D.; Pereira, L.; Pulli K.; Rusinkiewicz, S.; Shade, J. (2000). The Digital Michelangelo Project: 3D scanning of large statues. Proc. SIGGRAPH 2000

Chen, Y. H.; Ng, C. T. (1997). Integrated Reverse Engineering and Rapid Prototyping, Computers \& Industrial Engineering, Vol. 33, No. 3-4, pp. 481-484

Cosma, C.; Dume, A.; Tulcan, A.; Iclanzan, T. (2009). Rapid Development of Products using the Technique of Reverse Engineering, Annals of DAAAM for 2009 \& Proceedings of the 20th International DAAAM Symposium, 25-28th November 2009, Vienna, Austria, ISSN 1726-9679, ISBN 978-3-901509-70-4, Katalinic, B. (Ed.), pp. 0347-0348, Published by DAAAM International Vienna, Vienna

Fassi, F.; Fregonese, L.; Brumana, R.; Monti, C.; Achilee, C.; Cassani, C.; Vio, E. (2007). High density digital form for cultural heritage: synthetic modeling and reverse engineering of the four horses of the Basilica of San Marco in Venice, XXI International CIPA Symposium, 01-06 October 2007, Athens, Greece

Hong-Tzong, Y. (1997). Reverse Engineering of the engine intake ports by digitization and surface approximation, International Journal of Machine Tools and Manufacture, Vol. 37, No. 6, pp. 855-971, Elsevier Science Ltd

Rypl, D.; Bittnar, Z. (2006), Generation of computational surface meshes of STL models, Journal of Computational and Applied Mathematics, Vol. 192, pp 148-151

Sokovic, M. Kopac, J. (2006). RE (reverse engineering) as necessary phase by rapid product development, Journal of Materials Processing Technology, Vol. 175, pp. 398-403

Szilvasi-Nagy, M. \& Matyasi, Gy. (2003). Analysis of STL Files, Mathematical and Computer Modeling, Vol.38, pp.945-960 